\title{
JORNALISMO LITERÁRIO AVANÇADO E NARRATIVAS ARTESÃS: sinalizadores para a pesquisa em Turismo
}

ADVANCED LITERARY JOURNALISM AND ARTISANS NARRATIVES: signs for research in Tourism

PERIODISMO LITERARIO AVANZADO Y NARRATIVAS ARTESANAS: banderas para la investigación en Turismo

\section{Jennifer Bauer Eme}

Mestranda (Bolsista PROSUC/CAPES) no Programa de Pós-Graduação em Turismo e Hospitalidade da Universidade de Caxias do Sul (UCS). jbauer.eme@gmail.com.

0000-0003-4095-4944

\section{Maria Luiza Cardinale Baptista}

Doutorado em Ciências da Comunicação pela Universidade de São Paulo (USP). Professora Colaboradora do PPGCCOM UFAM e Professora Adjunta da Universidade de Caxias do Sul (UCS). conexaoucs@gmail.com.

\section{0-0002-7096-1160}

Correspondência: Universidade de Caxias do Sul, Centro de Ciências da Comunicação. Rua Francisco Getúlio Vargas, 1130. Petrópolis. 95070-560 - Caxias do Sul, RS - Brasil

Recebido em: 12.10 .2020$.

Aceito em: 20.11.2020.

Publicado em: 01.01.2021.

\begin{abstract}
RESUMO:
O presente texto tem como objeto de estudo a proposição de entrelaçamento do Jornalismo Literário Avançado (JLA) com a produção de 'narrativas artesãs', tendo como objetivo propor sinalizadores para a pesquisa em Turismo. $\mathrm{O}$ artigo apresenta o conceito de JLA e a compreensão de Turismo, como Trama-Ecossistêmica de Desterritorialização. Os aspectos metodológicos são compostos pela Cartografia de Saberes. Narrativas artesãs correspondem ao campo de pesquisa, com relatos de histórias de vida de artesãos de rua, entrelaçados com registros pessoais de diário de pesquisa. A produção permite pensar no JLA e as narrativas artesãs como campos de potencialidades, para a brotação de pesquisas que compreendam o Turismo e suas transversalidades, em sua complexidade.
\end{abstract}

PALAVRAS-CHAVES: Pesquisa; Jornalismo Literário Avançado; Narrativas artesãs; Turismo.

\section{Introdução}

O presente texto tem como objeto de estudo a proposição de entrelaçamento do Jornalismo Literário Avançado (JLA) com a produção de 'narrativas artesãs', tendo como objetivo propor sinalizadores para a pesquisa em Turismo.

A produção é decorrente de pesquisas desenvolvidas na Universidade de Caxias do Sul (UCS): a primeira realizada no período de Monografia, apresentada na graduação em Comunicação Social - Jornalismo, intitulada NARRATIVAS ARTESÃS: SINALIZADORES PARA O JORNALISMO AMOROSO. Aproximação com a Tribo Urbana de Artesãos de Rua em Caxias do Sul/RS (2016) e a segunda, em andamento, na produção da dissertação 'QUEM NÃO VIVE DO MAR, VIVE DE QUÊ?'. Sinalizadores de 'Repuxo' do Turismo em Torres/RS, analisados a partir de narrativas de moradores (2019-2021), no Programa de Pós-Graduação em Turismo e Hospitalidade (PPGTURH). Destaca-se o vínculo das produções com o Amorcomtur! - Grupo de Estudos em Comunicação, Turismo, Amorosidade e Autopoiese (CNPq-UCS). Em sentido mais amplo, este texto vincula-se, 
também, com outras pesquisas, desenvolvidas no PPGTURH, intituladas ECOSSISTEMAS TURÍSTICO-COMUNICACIONAIS-SUBJETIVOS: Sinalizadores Teórico-Metodológicos, no Estudo de Ecossistemas Turístico-Comunicacionais-Subjetivos, considerados a partir de sua característica Ecossistêmica, Caosmótica e Autopoiética (iniciada em 2018) e 'COMVERSAR' AMORCOMTUR! - LUGARES E SUJEITOS! Narrativas transversais sensiveis, envolvendo sujeitos em processos de desterritorialização - Brasil, Espanha, Portugal, Itália, México, Colômbia, Egito, Arábia Saudita e Índia (2020-2022).

As discussões sobre a prática comunicacional, a partir da produção de narrativas cotidianas, pautadas por uma lógica humanizada, sensível, entrelaçaram-se com o Turismo, na visão ecossistêmica. Mostraram-se um campo interessante, para refletir a atividade turística e o processo de pesquisa nessa área, também partindo de uma lógica sensível, considerando as singularidades e a complexidade ecossistêmica dos saberesfazeres desse universo de conhecimento.

A proposta contida nesse texto consiste em apresentar a relação estabelecida entre a história de vida de uma das pesquisadoras e as histórias de vida de artesãos de rua, em Caxias do Sul/RS, que contribuíram para a pesquisa apresentada em 2016. A pesquisa em andamento, no mestrado, reflete o amadurecimento da discussão, o entrelaçamento com os saberes-fazeres turísticos e a continuidade na reflexão sobre a produção de pesquisa, em Turismo. São estudos produzidos com os pressupostos característicos do Amorcomtur!.

É importante dizer, nesse momento do texto, que as pesquisas desenvolvidas no grupo de pesquisa são orientadas pela dimensão epistemológica de Ciência TramaComplexa, constituída por pensamentos entrelaçados com a visão holística e integrada de Ciência. Destacam-se, como autores dessa 'conversa' teórica, Roberto Crema (1989), Fritjof Capra (1992), Edgar Morin (2005).

Crema (1989) propõe o entrelaçamento entre visão holística e Ciência, chamando-o de paradigma holístico. Para ele, esse paradigma é constituído por princípios que consideram que cada elemento de um todo carrega um pouco desse todo, refletindo as dimensões do próprio campo. Outro ponto destacado pelo autor, no paradigma holístico, é a interação objeto-observador, apontando que o ser humano faz parte da dinâmica do Universo, podendo agir sobre ele, indo além do acaso e da casualidade (Crema, 1989).

Há aproximação, nesse sentido, com as ideias de Fritjof Capra (1992) que discute princípios da ecologia profunda, como a compreensão da ciência em sua dimensão integral, complexa e como uma trama de saberes diversos. "A percepção ecológica profunda reconhece a interdependência fundamental de todos os fenômenos, e o fato 
de que, enquanto indivíduos e sociedades, estamos todos encaixados nos processos cíclicos da natureza [...]" (Capra, 1992, p. 25).

Os aspectos apresentados pelos autores, substratos de orientação para as produções científicas no Amorcomtur!, alinham-se à proposição de uma atitude responsável ecossistemicamente, por parte de autores e pesquisadores. O sujeito que investiga reconhece a realidade como objeto de estudo, percebendo, também, as minúcias apresentadas pelo campo, os elementos bióticos e abióticos, materiais, abstratos e subjetivos que compõem a complexidade contemporânea na pesquisa.

A atitude de pesquisa que atribui características sensíveis, afetivadas - no sentido de afetivar, de tocar os afetos (Baptista, 2012) - é capaz de aproximar saberes múltiplos, ponto importante para a teoria da complexidade, apresentada por Morin (2005), a 'religação de saberes'. Além disso, o autor diz que compreender que os fenômenos sociais são compostos de uma relação transpassada, é considerar a complexidade como uma proposta de existência, onde é possível reconhecer os fios que formam a trama.

Dessa forma, as histórias de vida dos artesãos de rua, em Caxias do Sul/RS, marcadas pelas cenas cotidianas de seus deslocamentos, transpassaram-se à história de vida da pesquisadora agora mestranda, que 'encontrou sua tribo' por meio do fazer artesanal, refletindo-se na produção da pesquisa e sustentando, subjetivamente, a discussão sobre os saberes-fazeres turísticos, no mestrado. Compreende-se, assim, que compartilhar as histórias desses personagens, em narrativas artesãs, consideradas a partir do JLA, seja potencialidade para a pesquisa em Turismo e suas transversalidades, podendo contribuir de alguma maneira, para pensar sobre a produção da pesquisa qualitativa.

Por ora, pontua-se que este texto apresenta, em seus itens: a perspectiva de Jornalismo Literário Avançado (JLA); a estratégia metodológica Cartografia de Saberes, em que se destaca a Trilha Saberes Pessoais, na construção de narrativas comunicacionais e científicas - na costura de saberes múltiplos; as narrativas artesãs com o entrelaçamento das histórias de vida dos artesãos de rua e da pesquisadora; e as considerações finais, no fechamento da discussão sobre a pesquisa em Turismo.

\section{Jornalismo Literário Avançado}

O conceito de JLA, apresentado por Edvaldo Pereira Lima (2009) e desenvolvido também por Monica Martinez (2019), tem como uma de suas bases a ruptura em relação ao atrelamento da prática comunicacional com a objetividade e o reducionismo cartesiano da Ciência Moderna. Além disso, há o questionamento em relação aos processos de individualização e produção em série da Revolução Industrial. 
Cremilda Medina (1993) fala que essa ruptura transformou o século XX na Era das Incertezas, estando a comunicação intrinsecamente envolvida com a construção de uma nova forma de olhar e pensar a sociedade. Nesse sentido, a relação jornalismo-literatura foi proposta pelo Jornalismo Literário, como alternativa de contar a realidade, o cotidiano, com a produção de narrativas entrelaçadas com técnicas da escrita literária, com transversalizações da poética desse gênero de escrita.

Para Lima (2009), no entanto, é preciso ir além nessa relação e considerar a narrativa jornalística, a partir de outras linguagens. O JLA avança na compreensão da relação jornalismo-literatura, abrindo o campo narrativo cotidiano para outras técnicas, não só de escrita, como arte, dança, música, fotografia, pintura, artesanato, etc.

No entrelaçamento de práticas, para produzir a narrativa jornalística, o autor incorpora na compreensão do JLA a concepção de viagem, descrevendo a prática como

[...] uma viagem de descoberta pelo território do real, por todos os mundos que constituem aquilo que achamos que é a realidade. A literatura do real muda dinamicamente ao longo do tempo, como tudo o que existe. Nada é estático, apenas nossos olhos aceitam ilusões. Tudo está em movimento. O tempo todo. (Lima, 2009, p. 436).

Dessa viagem, no deslocamento feito entre os sujeitos e a narrativa, Monica Martinez apresenta outra característica da modalidade de escrita jornalística: a capacidade de estabelecer afeto e laços, por meio da narrativa (Martinez \& Heidemann, 2019). As narrativas produzidas, a partir do JLA, por considerarem os detalhes da cena cotidiana, aproximam o leitor da complexidade da realidade. "Ao imergir nos sabores e dissabores de determinada narrativa, o leitor pode ser afetado por ela e, posteriormente desenvolver um vínculo com o que foi narrado, assim como com determinado personagem ou até mesmo com o estilo do(a) autor(a)" (Martinez \& Heidemann, 2019, p. 11).

Para alcançar com profundidade e tratar a realidade em sua complexidade, na narrativa - segundo o JLA -, o autor precisa mergulhar na cena, no real, abastecer-se de múltiplas técnicas para contar a história, mas, antes disso, é preciso relacionar-se com proximidade da realidade.

Assim também acontece com a pesquisa (em Turismo, nesse caso). O sujeito que investiga precisa mergulhar no campo, caminhar com os sentidos atentos como quem caminha na floresta pela primeira vez. As interações com a dimensão da pesquisa, seja teórica ou empírica, são momentos marcados por singularidades que devem contribuir para a produção do conhecimento científico e para o amadurecimento do pesquisador. 
Se a relação com o objeto de estudo é de proximidade, de mergulho, são maiores as chances de a investigação pensar tal objeto de forma holística, integrada.

Outra proposição interessante do Jornalismo Literário Avançado é a transdisciplinaridade. O JLA "[...] integra, em síntese, contribuições de distintos campos de conhecimento, alavancando um novo conjunto de paradigmas para a compreensão do real" (Lima, 2009, p. 439). Fazem parte, também, das premissas do JLA a física quântica, com a ideia de constituição do macro espaço por micros espaços de energia, e a teoria dos campos morfogenéticos "[...] que mostra a conexão não racional entre seres de uma mesma espécie, ultrapassando fronteiras de tempo e espaço [...]" (Lima, 2009, p. 441).

A transdisciplinaridade marca também os saberes-fazeres turísticos, transversalizando diversos universos de conhecimento, na produção de conhecimento científico do Turismo. Isso acontece no presente texto, por exemplo, com o entrelaçamento de Comunicação, do próprio JLA e das narrativas artesãs, na construção de sinalizadores para o processo de pesquisa. A transdisciplinaridade é um dos aspectos que possibilita compreender o Turismo como Trama-Ecossistêmica, partindo do pensamento de Mario Beni e Marutschka Moesch (2017), Susana Gastal (2002) e da visão de Ecossistema Turístico de Maria Luiza Cardinale Baptista (2020).

Assim, a relação proposta no presente texto busca contribuir para o desenvolvimento de pesquisa na interface Turismo-Comunicação, campos pensados como tramas-ecossistêmicas. Neste caso, consideram-se as narrativas artesãs, pautadas pelo JLA, percebidas no movimento - investigativo, turístico, comunicacional - e marcadas pela complexidade contemporânea.

\section{Cartografia de Saberes}

Os aspectos metodológicos são compostos, principalmente, a partir da estratégia metodológica Cartografia de Saberes (Baptista, 2014, 2017, 2020). Ressalta-se que a Cartografia de Saberes é considerada uma estratégia, porque se constitui como uma orientação do pensamento que se direciona para a ação, visando à execução. No caso da pesquisa, é uma estratégia que direciona aproximações e ações em uma lógica complexa, processual, rizomática e caosmótica. Nesse sentido, existe a possibilidade de que venha a ser combinada com métodos e técnicas, já tradicionais, dependendo do alinhamento com o objeto do estudo.

A Cartografia de Saberes convida o investigador a saborear o trajeto da pesquisa, valorizando o aspecto subjetivo, que potencializa o sujeito para a produção. Sua organização em quatro grandes trilhas (Trilha Saberes Pessoais, Trilha Saberes Teóricos, 
Trilha Usina de Produção e Trilha Dimensão Intuitiva da Pesquisa) estabelece uma relação de proximidade com o objeto; propõe uma aproximação amorosa - no sentido da ética da relação e da intensidade de afeto - com os autores e suas teorias; e permite entrelaçar o conhecimento teórico com a prática ao desenvolver-se a pesquisa de campo.

Desenvolvida por Baptista, ao longo de mais de 30 anos de pesquisas e docência em Metodologia da Pesquisa, essa estratégia metodológica deriva da proposta apresentada por Suely Rolnik, de transposição do conceito da geografia, para o universo metodológico, especialmente vinculado aos territórios existenciais psicossociais. Rolnik (2006) afirma que a Cartografia é o desenho que se faz da paisagem, acompanhando suas alterações. Segundo a autora, a cartografia é feita no movimento de desmanchamento de mundos e construção de outros: "[...] mundos que se criam para expressar afetos contemporâneos, em relação aos quais os universos vigentes tornamse obsoletos" (Rolnik, 2006, p. 23).

Do Manual do Cartógrafo de Rolnik (2006), em associação a uma trama de autores e inspirações da experiência empírica, como pesquisadora e docente, Baptista propôs a trama de trilhas da Cartografia de Saberes. Trata-se de uma estratégia que envolve pressupostos que auxiliam o pesquisador a relacionar a complexidade da realidade cotidiana com a pesquisa que desenvolve. Ela permite enxergar as trilhas por onde a pesquisa pode seguir, lembrando que esse processo está em constante mutação, reinventando-se a todo momento, onde "Todas as entradas são boas, desde que as saídas sejam múltiplas" (Rolnik, 2006, p. 65, grifo da autora).

Como foi dito anteriormente, existem quatro grandes trilhas que compõem a Cartografia de Saberes. Essas trilhas acontecem sem hierarquização ou sobreposição, todas elas têm o mesmo caráter de importância para a pesquisa. A postura de desenvolver as trilhas em paralelo é coerente com a proposição de Rolnik (2006) e também com o cenário de mutação da Ciência, em que a paisagem se altera constantemente, movendo-se. Por isso é importante compreender a dinâmica das trilhas, revisitando-as para novos registros e leituras.

De qualquer forma, por orientação de Baptista (2014), é interessante que o investigador inicie pela Trilha Saberes Pessoais. Isso, porque, para a autora, é o momento em que "o investigador deve procurar refletir sobre o que sabe sobre o assunto" (Baptista, 2014, p. 350).

A Trilha Saberes Teóricos é responsável pela escolha dos autores, que acompanharão o investigador durante o desenvolvimento da pesquisa. Então, depois de definir o que se sabe, a priori, do tema escolhido e de definir os conceitos principais que 
orientam a pesquisa, trabalha-se com a definição dos teóricos que sustentam as proposições apresentadas pelo pesquisador. Com isso, parte-se para a sistematização das referências, conforme orientação de Baptista (2014, p. 351),

[...] proponho que o pesquisador monte um quadro com os assuntos e as referências teóricas encontradas sobre cada um deles. Esse quadro é importante, porque ajuda a visualizar a cartografia teórica e suas linhas investigativas. [...] Trata-se, aqui, também, de um quadro-esboço cartográfico que se refaz o tempo todo, destacando os textos já lidos, já trabalhados efetivamente.

O processo de interação com os autores, além de essencial para a construção do texto científico, reforça e aprimora os saberes pessoais do pesquisador.

Outra grande trilha é a Usina de Produção, que trata das aproximações e ações investigativas, que vão sendo empreendidas pelo pesquisador, para 'viver a pesquisa'. Baptista (2014) indica que, tanto as aproximações quanto às ações investigativas, devem ser escolhidas conforme o tipo de pesquisa, o objeto de estudo. Como aproximações, a autora sugere "[...] observação sistemática, conversas informais, exploração preliminar de material e/ou documentos, enfim, devem ser acionadas técnicas de aproximações com o fenômeno a ser estudado" (Baptista, 2014, p. 351).

É preciso destacar a importância de registrar as experiências em Diário de Pesquisa "[...] uma espécie de diário de bordo, dessa viagem intelectual, que é o conhecimento produzido na pesquisa" (Baptista, 2014, p. 351).

A última grande trilha da Cartografia de Saberes é a Trilha Dimensão Intuitiva da Pesquisa. Essa trilha dimensiona que o conhecimento não é produzido somente em nível consciente, "[...] nas instâncias do pensamento racional. Quando alguém investiga, esse sujeito investe-se em direção ao objeto paixão-pesquisa e isso significa que o sujeito todo pesquisa e vibra com a investig[ação]" (Baptista, 2014, p. 352). Assim, é possível que a solução para o problema de pesquisa surja de um momento de 'não pesquisa', onde o pesquisador conecta-se com níveis abstratos, inconscientes, despertando aspectos teóricos e de análise do objeto antes não notados pelo pesquisador.

A trilha possibilita, também, que o pesquisador perceba detalhes subjetivos das cenas, uma espécie de "captura" do que não foi dito com materialidade pelo campo. Os entrelaçamentos que sustentam a trama pesquisada aproximam-se do pesquisador pela Trilha Dimensão Intuitiva da Pesquisa.

Como a proposta do presente artigo relaciona-se profundamente com a Trilha Saberes Pessoais, é importante percorrê-la com mais atenção que as demais. Portanto, este momento do texto é dedicado à caminhada pela Trilha Saberes Pessoais e suas contribuições para as 'pesquisas-matrizes' e para o presente texto. 
Baptista (2014, p. 350) diz que "Quem escolheu um assunto para pesquisar é porque 'sabe algo' sobre isso - mesmo que intuitivamente", portanto a recomendação é de que o pesquisador inicie o caminho seguindo essa trilha. $O$ exercício de escrever o que já sabe ajuda a compreender por onde a pesquisa pode seguir e dá confiança ao investigador que se sente mais próximo ao assunto. Essa escrita estimula um devir pesquisa, o que Rolnik (2006) chamaria de "estratégias do desejo", nesse caso: estratégias do desejo de pesquisar.

A Trilha tem destaque, pois os saberes pessoais de uma das pesquisadoras levaram-na para o encontro com a tribo urbana dos artesãos de rua, já que, antes da relação com a comunicação e a pesquisa, havia a relação com aqueles sujeitos que ela encontrava no caminho diário para o trabalho. Além disso, a relação com o artesanato vem do ambiente familiar, crescendo com a avó, a mãe e a irmã artesãs e tendo, ela mesma, a produção como recurso financeiro no início da graduação.

Reconhecer o fazer artesanal como contribuição para (re)pensar a prática jornalística já era um dispositivo de afetivação para o desenvolvimento da pesquisa; porém, a interação com os artesãos de rua, em Caxias do Sul/RS, mostrou-se essencial para apresentar, na pesquisa, questionamentos sociais, provocados por sujeitos pouco reconhecidos como sujeitos de suas próprias vidas, personagens do cotidiano que também tem algo a dizer.

Os aspectos abordados pelos artesãos de rua permitiram aprofundar a discussão desenvolvida em entrelaçamento com o Turismo, com desdobramentos voltados para o processo de desterritorialização, causado pela condição nômade dos artesãos de rua. Dessa forma, percebe-se que a aproximação de saberes múltiplos: saberes pessoais da pesquisadora, saberes pessoais dos artesãos e saberes teóricos, contribuiu, também, para a pesquisa em Turismo, mostrando outra possibilidade de produção de conhecimento e de reconhecimento dos diversos recursos teóricos e empíricos na pesquisa.

Por terem caráter autoral, de histórias de vida, os relatos serão apresentados 'costurados' à discussão do presente trabalho (numa produção de pesquisa artesã). Na seção seguinte, o texto apresentado é composto por trechos de falas dos artesãos de rua e trechos da Trilha Saberes Pessoais da pesquisadora; portanto, em primeira pessoa, tramados por reflexões epistemológicas-teóricas já mencionadas no texto.

\section{Narrativas Artesãs}


"Quando eu tô produzindo na rua a vibe é a que tem naquele momento, tá ligado? Eu tenho que entender que as pessoas vão parar pra conversar ou que eu vou mudar de lugar... essas paradas vão ficar na peça que eu tiver fazendo na hora." (Pedrinho ${ }^{1}, 2016$, grifo nosso).

Compreende-se ser coerente com a visão epistemológico-teórica deste texto iniciar a seção já com um trecho da fala de um artesão de rua. A partir dela, propõe-se a discussão sobre a dimensão complexa da pesquisa em Turismo. Pedrinho afirma que a produção artesanal, na rua, é constituída pelo que ela proporciona. Além dos materiais disponíveis, as interações que surgem, no processo de produção, se refletem no artesanato, nas amarras das linhas ou no traço marcado pelo alicate no metal.

A pesquisa, em Turismo, é marcada por essa diversidade. A 'rua' da pesquisa deixa suas marcas no sujeito pesquisador e na produção apresentada por ele. As interações com o campo partem da 'vibe' daquele momento, o que faz com que a pesquisa seja flexível, no sentido de desenvolvimento de abordagens diferentes, necessárias com as alterações 'da paisagem investigativa'. Reconhecer isso significa reconhecer a dimensão complexa do campo, que precisa ser 'costurado' com calma, de maneira artesã, do modo orientado pela artesania. Nesse processo, reconhece-se uma trama de fios e nós, trançados na composição da pesquisa. Além das marcas apresentadas pelo pesquisador, há outras que podem constituir outros caminhos de investigação.

Conforme dito anteriormente, compreende-se Turismo como TramaEcossistêmica de Desterritorialização, sendo ele o desenvolvimento de um pensamento turístico potencializador de sujeitos, envolvidos na trama ecossistêmica do lugar em que a prática turística acontece. Esta compreensão estende-se para a prática de pesquisa em Turismo. Nos estudos do Amorcomtur!, a dimensão trama transversaliza Ciência, Turismo, Comunicação e Subjetividade.

Nesse sentido, conforme Beni e Moesch (2017, p. 432),

Turismo é processo humano, ultrapassa o entendimento como função de um sistema econômico. Como um processo singular, necessita de ressignificação às relações impositivas, aos códigos capitalísticos e aos valores colocados como patrimonialização cultural.

Portanto, pensar o turismo hoje é voltar-se a uma complexa trama de olhares, que se debruça por um caminho cheio de entrelaçamentos, que se 'costuram' em um meio social. Trata-se da trama de um fenômeno multi-inter-transdisciplinar, como

\footnotetext{
${ }^{1}$ Os personagens que aparecem no artigo tiveram seus nomes alterados, como forma de preservar suas privacidades. Os codinomes utilizados aqui são os mesmos utilizados na pesquisa Narrativas Artesãs, de 2016.
} 
apontado por Lima e Baptista (2017), que se desloca como em uma viagem, através de percurso de conceitos, definições, debates.

Nesse sentido, como dispositivo potencializador de sujeitos e considerado como processo humano, social, artesãos de rua e turistas são envolvidos pelo desejo de movimento. Ao responder à provocação "me conta tua história", feita pela pesquisadora, os artesãos de rua relatavam a relação que estabeleciam com outros artesãos, que contavam suas histórias de estrada.

\begin{abstract}
"Eu já queria sair de casa, queria me sustentar com um trampo legal, que eu gostasse. Aí um dia, na casa de um vizinho tinha um maluco que fazia artesanato pra vender na rua, ia passar um tempo alugando um quarto. Cara, quando eu ouvi as histórias dele tinha certeza que ia pegar a estrada, junto (risos)." (Téo, 2016, grifo nosso).

"Na praia, ainda novinho, sempre parava pra vê as artes dos carinhas que ficavam na calçada. Comprava alguma coisa, às vezes, só que eu sempre puxava papo, dizia que sabia fazer uns pontos, aprendia outros (risos). Gostava mesmo era de sentir a liberdade que eles tinham, de escutar as histórias que eles contavam. Resolvi fazer artesanato pra conhecer outros lugares, poder viajar também." (Jean, 2016).
\end{abstract}

Da 'contação' de histórias de vida dos artesãos de rua, brotou a reflexão sobre a potencialidade desejante das narrativas de viagem, no Turismo. Nesse sentido, também o desejo de ser sujeito da própria vida, de sentir-se construindo o próprio caminho. Destaca-se o registro feito em diário de pesquisa na construção da Trilha Saberes Pessoas da pesquisadora, como entrelaçamento de saberes na pesquisa:

"[...] me parece que a sensação de liberdade que a forma de trabalho proporciona aos artesãos é o que mantém eles em movimento. Também acho que poder viver da sua arte significa sustentar sua vida, com o que as mãos são capazes de produzir. Isso pode encorajar as pessoas em querer viver a vida de 'maluco de estrada'." (Pesquisadora, 2015).

Esse entrelaçamento, importante para a 'religação de saberes', conforme Morin (2005), expressa a diversidade de aspectos que podem surgir na pesquisa em Turismo e suas transversalidades, a ideia é reforçada pelo entrelaçamento entre os universos de conhecimento do Turismo e da Comunicação, na construção dos saberes-fazeres turísticos.

Outro aspecto importante, que brotou das histórias de vida, refere-se ao pensamento comunitário, acolhedor que transversaliza as relações dos artesãos de rua.

"Ninguém nasceu pra viver sozinho. Nós nascemos pra viver em comunidade. O ser humano sempre precisou e vai sempre precisar de gente pra progredir, pra sobreviver. É isso que as pessoas de hoje ainda 
não se deram conta. Elas não vão viver bem porque elas têm mais ou menos grana, tá ligado? Elas vão viver bem se elas estiverem com quem elas gostam por perto. O que todo mundo precisa entender é isso, aí sim o mundo vai ser bom." (Pedrinho, 2016, grifo nosso).

"Quando a gente acolhe a gente mostra pra outra pessoa que ela é igual a nós. Que ela só escolheu viver de outra forma. Ela tá presa no sistema que eu tô aqui, me libertando. Mas todo mundo é filho de Deus, então temos que nos tratar igual." (Clarinda, 2016, grifo nosso).

Acredita-se que assim também deve acontecer com a/na pesquisa, é preciso reconhecer outros saberes, que se divergem ou se complementam, mas que se aproximam, de uma forma ou de outra, na proposição de conhecimentos sobre o assunto estudado. Acolher o outro, na pesquisa em Turismo, pode significar olhar para lugares turísticos partindo de olhares novos, como é o caso da pesquisa desenvolvida no mestrado - 'Quem não vive do mar, vive de quê? (2019-2021) - em que a discussão é proposta pela relação dos moradores com a cidade e com a atividade turística.

A concepção de que a produção, seja ela artesã ou científica, pode contribuir para - desenvolvimento de uma realidade pautada pelas ideias de responsabilidade ecossistêmica e de amorosidade, no sentido de 'ética da relação' (Maturana, 1998), propõe a reflexão sobre a produção de conhecimento e o diálogo da academia com a sociedade. Esses pontos aparecem tanto do registro da pesquisadora como na fala de uma artesã:

\footnotetext{
"É interessante pensar que eu e os artesãos de rua vemos o artesanato como um meio de vida, mas em 'sistemas' diferentes. Somos aproximados pela ideia de mostrar como o artesanato é importante para muita gente, mas será que meu sentimento de 'pesquisadoraartesã' também não se relaciona com a compreensão de mundo desses sujeitos? Penso que minha pesquisa serve para dar espaços às narrativas de sujeitos que só aparecem no jornalismo quando é preciso expressar o exótico, o que foge à normalidade. Sei que essas pessoas podem assumir papeis mais importantes." (Pesquisadora, 2015).

"Olha só tu aqui no nosso meio. Isso é lindo, cara! Como tu diz, tu tá levando a rua pra dentro da academia, tu tá fortalecendo um pensamento que a gente já cultiva aqui. Eu li muito sobre Marx, e li também muito Bourdieu, muito Foucault pra defender o que eu acredito." (Cláudia, 2016).
}

\section{Considerações finais}

O entrelaçamento entre as duas pesquisas que fez brotar o presente artigo proporcionou um novo contato com os registros da pesquisa desenvolvida em outro momento, permitindo que outras reflexões fossem feitas, tanto sobre o material apresentado, quanto sobre a pesquisa em andamento. Revisitar a Trilha Saberes Pessoais 
e os relatos dos artesãos de rua, em Caxias do Sul/RS, aciona 'novos' campos abstratos para sentir a pesquisa e mostra aspectos que podem contribuir para a aproximação com as narrativas dos moradores de Torres/RS, no texto para o mestrado. Esses desdobramentos, da visita ao material registrado, são tratados, dessa forma, como resultados intrínsecos no presente texto produzido.

Partindo para as considerações sobre o objetivo do artigo - propor sinalizadores para a pesquisa em turismo, a partir da experiência com as narrativas artesãs e do JLA - a reflexão apresenta aspectos interessantes para refletir o 'fazer' pesquisa, em Turismo.

É preciso dizer que se percebe, nas práticas comunicacional e turística, marcas da lógica da produção em série, impessoalizada, a partir de processos mecanizados, com forte presença de aparato maquínico e/ou tecnológico, que caracteriza o sistema de produção pós-Revolução Industrial. Todo esse desenvolvimento, no entanto, pautou-se pelos pressupostos da Revolução Científica: mecanização da produção, fragmentação dos processos, ênfase na produtividade, considerada a partir de vieses matemáticos e ênfase na manifestação concreta dessa produção. Dessa forma é possível perceber as características também no cenário científico.

$\mathrm{Na}$ atividade turística, especialmente, essas características ficaram visíveis a partir do século XX, com o avanço dos estudos que priorizaram a dimensão econômica do Turismo ${ }^{2}$. O Turismo de massa e o processo de turistificação podem transformar o lugar em cenário de disputas relacionais, entre residentes e turistas, pois esse processo pode fragmentar a destinação turística, como é o caso de Barcelona, na Espanha: a cidade catalã viu seu turismo crescer depois das Olimpíadas de 1992 e, atualmente, sofre com manifestações de moradores contra turistas, como a turismofobia.

O Turismo é um universo de conhecimento, envolvendo saberes e fazeres, marcadamente transdisciplinar. Os estudos epistemológicos desse campo vêm se desafiando, no sentido de compreender a complexidade da composição, associada à velocidade das transformações.

Nesse sentido, o Jornalismo Literário Avançado, na condição de contraponto ao reducionismo, fragmentação e produtividade discursado pela Ciência Moderna, na Comunicação, ressalta essas marcas, também, no Turismo. A aproximação somente da dimensão econômica da atividade, fragmentou os estudos no universo de

\footnotetext{
2 Um levantamento minucioso, em linha de tempo, do conceito de Turismo foi feito por Helena Charko Ribeiro, em tese de doutoramento intitulada Turismo e Saúde: sinalizadores turísticos de Porto Alegre, relatados pelos usuários do Sistema Único de Saúde (SUS) e seus acompanhantes, em processos de deslocamento, apresentada em 2019, no PPGHTUR.
} 
conhecimento. Os aspectos de contemplação do todo, que sustentam o JLA, podem ajudar o processo de pesquisa em Turismo a considerar a complexidade e a dinâmica que uma área transdisciplinar tem.

A proposta de mergulho na realidade para compor a narrativa jornalística, trazida pelo JLA, pode ser levada para o Turismo, como forma de olhar o cotidiano, a prática, os fazeres de uma destinação turística, reconhecendo o ecossistema e, a partir disso, propor saberes que sejam mais próximos da teia-trama que compõe o lugar. Acredita-se que, assim como a narrativa jornalística, a narrativa científica também precisa desse mergulho na realidade, antes de ser contada à sociedade, num exercício mútuo de aproximação. Além disso, demanda uma ampliação da sensibilidade, para a captação de detalhes, apreensão de universos abstratos de significação.

Além desses dois sinalizadores, o JLA contribui ainda, com a pesquisa em Turismo, ao sustentar que as múltiplas práticas e técnicas são importantes para produzir a narrativa cotidiana. Assim como é possível na Comunicação munir-se com diversos instrumentos para tecer a narrativa, a Ciência também é campo para refletir sobre isso. Os pesquisadores costumam produzir suas investigações, considerando as múltiplas práticas e técnicas? Como elas se relacionam? Isso implica um investimento - como processo inerente da investigação - plurimetodológico, cartográfico, na compreensão dos ecossistemas complexos.

Uma realidade complexa, como a correspondente ao Turismo, como TramaComplexa de Desterritorialização, precisa ser sentida, percorrida, com o auxílio da multiplicidade, buscando a composição rizomática de uma trama de dispositivos que possibilitem os diversos percursos investigativos, com aproximações e ações investigativas. Aqui é possível perceber o sinalizador que brota das narrativas artesãs, 0 pressuposto conceitual Artesania. O pressuposto tem sido discutido pelas pesquisadoras em estudos transversais as pesquisas em andamento.

Entre as reflexões que Artesania permite, na pesquisa em Turismo, destaca-se que a ideia surge como contraposição aos pressupostos epistemológicos citados anteriormente, nesta seção. O sujeito 'pesquisador-artesão' se reconhece na pesquisa. Ele tece a teia-trama, sabendo-os um fio componente, trançado e trançador. Assim, deixa um pouco de si no saber construído, faz e refaz o caminho percorrido até a produção da 'peça' - artigo, relatório, projeto, monografia, dissertação ou tese. Ele também se transforma a partir dela ao longo do processo. Na lógica artesã, o processo de produção é tão (ou mais) relevante que o resultado final, ou seja, o caminho percorrido, os fios da trama, as descobertas, os pontos levantados devem ser reconhecidos como saberes 
também. A trama que se forma do entrelaçar dos fios pode ajudar a considerar aspectos interessantes do objetivo principal.

Por fim, num segundo momento de coerência com a visão epistemológicateórica do presente texto, considera-se conclui-lo com a fala da pesquisadora, ao final da investigação construída com os artesãos de rua, em Caxias do Sul/RS. Uma narrativa tecida a muitas mãos, entrelaçando saberes enquanto acionavam seus fazeres, em movimento.

Com os artesãos de rua a futura jornalista que vos fala aprendeu o cuidado de tramar um texto como se trama os fios de um entrelaçamento forte e capaz de apresentar a vida composta e compartilhada com pessoas de pensamento definido e abertas a reconhecer o mundo todos os dias. Fica sinalizada, assim, a importância do outro na narrativa jornalística, não como fonte, mas como protagonista de sua própria história. (Pesquisadora, 2016).

\section{Referências}

Baptista, M. L. C. (2020). "Amar la trama más que el desenlace!": Reflexões sobre as proposições Trama Ecossistêmica da Ciência, Cartografia dos Saberes e Matrizes Rizomáticas, na pesquisa em Turismo. Revista de Turismo Contemporâneo, 8(1), 4164.

Baptista, M. L. C. (2014). Cartografia de saberes na pesquisa em Turismo: proposições metodológicas para uma Ciência em Mutação. Rosa dos Ventos, 6(3), 342-355.

Baptista, M. L. C. (2012). Jornalismo amoroso. Quem quer (a)provar? Reflexões sobre a aplicação de práticas pedagógicas amorosas, na formação e no cotidiano do jornalista. REBEJ - Revista Brasileira de Ensino de Jornalismo, 1(9), 93-118.

Beni, M. C., \& Moesch, M. (2017). A teoria da complexidade e o ecossistema do turismo. Turismo-Visão e Ação, 19(3), 430-457.

Capra, F. (1992). O ponto de mutação. (13ª ed.). São Paulo: Pensamento-Cultrix.

Crema, R. (1989). Introdução à visão holística. (5a ed.). São Paulo: Summus.

Gastal, S. de A. (2002). Turismo: 9 propostas para um saber-fazer. Porto Alegre: EDIPUCRS.

Lima, E. P. (2009). Páginas ampliadas: o livro-reportagem como extensão do jornalismo e da literatura. ( $3^{\mathrm{a}}$ ed.). Barueri: Manole.

Lima, R. dos S., \& Baptista, M. L. C. (2017). Cartografia de saberes: novas reflexões sobre os caminhos metodológicos do turismo no Círio de Nazaré. Revista Iberoamericana de Turismo- RITUR, 7(2), 175-201.

Martinez, M., \& Heidemann, V. (2019). Jornalismo Literário: afeto e vínculo em narrativas. Lumina, 13, 4-14, 2019.

Maturana, H. R. (1998). Emoções e linguagem na educação e política. Belo Horizonte: UFMG.

Medina, C. (1993). Desafio das interfaces. In Medina, C., \& Greco, M. (Orgs.). Do Hemisfério Sol. O discurso fragmentalista da Ciência (Coleção Novo Pacto da Ciência - 2; pp. 17-20) São Paulo: ECA/USP.

Morin, E. (2005). Ciência com consciência. (8 $8^{\mathrm{a}}$ ed.). Rio de Janeiro: Bertrand Brasil. 
Rolnik, S. (2006). Cartografia sentimental: transformações contemporâneas do desejo. São Paulo: Estação Liberdade. 


\section{Qrevisto Observatório}

\section{ABSTRACT:}

The present text has the purpose of studying the proposition of entanglement of the Advanced Literary Journalism (ALJ) with the production of "artisans' narratives", having as purpose to propose signs for research in Tourism. The article presents the concept of the $A \sqcup$ and the comprehension of Tourism, as Ecosystemic-Path of Deterritorialization. The methodological aspects are composed by the Cartography of Knowledge. Artisans narratives correspond to the field of research, with relates of life stories from street artisans, entangled with personal records from the diary of research. The production allows thinking on ALJ and the artisans narratives as fields of potentialities, for the upcoming of researches that comprehend Tourism and its transversalities, in its complexity.

KEYWORDS: Research; Advanced Literary Journalism; Artisans Narratives; Tourism.

\section{RESUMEN:}

El presente texto tiene como propósito estudiar la propuesta de enredo del Periodismo Literario Avanzado (ALJ) con la producción de "narrativas de artesanos", teniendo como propósito proponer signos para la investigación en Turismo. El artículo presenta el concepto de AL y la comprensión del Turismo, como Camino Ecosistémico de Desterritorialización. Los aspectos metodológicos están compuestos por la Cartografía del Conocimiento. Las narrativas de los artesanos corresponden al campo de la investigación, con relatos de historias de vida de artesanos callejeros, entrelazados con registros personales del diario de investigación. La producción permite pensar en ALJ y las narrativas de los artesanos como campos de potencialidades, para el surgimiento de investigaciones que comprendan el Turismo y sus transversalidades, en su complejidad.

PALABRAS-CAVES: Investigación; Periodismo literario avanzado; Narrativas de artesanos; Turismo. 